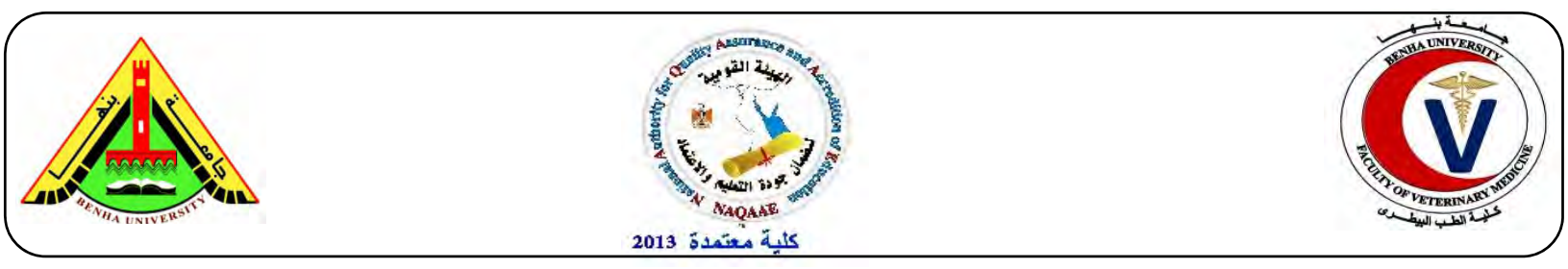

\title{
Molecular study on the potential therapeutic effect of novel nanocompsite on cancerous tumor bearing mice
}

\author{
Omayma A.R. Abou Zaid, Hussein AbdEl Maksoud, Abdel Fatah M. Badwi, Mohamed A. \\ Hussien and Mohammed F. EL-Shiekha \\ Department of Biochemistry, Faculty of Veterinary Medicine, Benha University, Qalioubeya, Egypt.
}

\section{A B S T R A C T}

Nanoparticles are making significant contributions to the development of new approaches of drug delivery in cancer and can provide a platform for combined therapeutics with subsequent monitoring of response. Basic curcumin and zinc oxide $(\mathrm{ZnO})$ nanocompsite modified with vitamin $\mathrm{C}$ and $\mathrm{CTAB}$ have been exert chemopreventative activity against cancer in mice animal model. This study was carried out on 80 mice and were divided into four groups, each groups have (20 mice) Group 1: NTBM (Negative control) .Group 2: TBM- (Positive control). Group 3: NTBM-treated with nanocompsite orally (1.850 $\mathrm{g} / \mathrm{kg} /$ day) for 6 weeks. Group 4: TBM-treated with nanocompsite orally $(1.850 \mathrm{~g} / \mathrm{kg} /$ day $)$ for 6 weeks. Liver tissues sample were collected from all mice by decapitation after 2, 4 and 6 weeks from the onset of treatment, then obtained in dry and clean tubes then kept in a deep freeze at $-20^{\circ} \mathrm{C}$ and processed, total RNA isolation and quantitative real time PCR analysis for apoptotic marker (P53- gene expression), apoptotic DNA ladder assay and estimation of protein. We observed that nanocompsite have distinct effects on liver cell viability via killing cancer cells, while posing no effect on normal cells (hepatocytes). The marked difference in cytotoxicity between cancer cells and normal cells suggests an exciting potential for nanocompsite as novel alternatives to cancer therapy. Our molecular data showed that both mRNA and protein levels of tumor suppressor gene p53 were upregulated and induce activity of DNA fragmentation in liver cells.

Key Words: Curcumin nanoparticles, Zinc Oxide nanoparticles, P53- gene expression

(http://www.bvmj.bu.edu.eg)

(BVMJ-28(1): 98-108, 2015)

\section{INTRODUCTION}

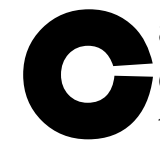
ancer is a hyperproliferative disorder marked by metastasis into the vital organs of the body through invasion and angiogenesis. Cancer chemotherapy is often associated with the side effects on immune cells. Thus, the prerequisites for anti cancer drugs are to ensure no damaging affects on the immune cells, failing which the drug may completely terminate the subsided immune response in tumor-bearing host (Aggarwal et al., 2006). Apoptosis is a key process in cancer development and progression. The ability of cancer cells to avoid apoptosis and continue to propagate is one of the fundamental hallmarks of cancer and is a major target of cancer treatment. Apoptosis is controlled by a large number of genes acting as death switches. The tumor suppressor gene p53 is regarded as the master guardian of the cell and is able to activate cell-cycle checkpoints, DNA repair, and apoptosis to maintain genomic stability (Sherr, 2004). In the presence of DNA damage, p53 protein triggers cellcycle arrest to provide time for the damage to be repaired or for self mediated apoptosis (Farnebo et al., 2010). Nanotechnology allows the manipulation of materials at nanoscale level (1-100 nm), which enables precision engineering to control nanoparticles' (NPs') physicochemical properties, as well as their interactions with biological systems (Lee et al., 2007). 
Inorganic NPs, including metal oxides, are promising materials for applications in medicine, such as cell imaging, biosensing, drug/gene delivery, and cancer therapy (Wu et al., 2011). Zinc oxide (ZnO) NPs belonging to a group of metal oxides are characterized by their photocatalytic and photo-oxidizing ability against chemical and biological species. In recent times, $\mathrm{ZnO}$ NPs have received much attention for their implications in cancer therapy (Zhang et al., 2011). Studies have shown that ZnO NPs induce cytotoxicity in a cellspecific and proliferation-dependent manner, with rapidly dividing cancer cells being the most susceptible, and quiescent cells being the least sensitive (Premanathan et al., 2011). Curcumin, a polyphenolic compound extracted from rhizomes of Curcuma species, has been shown to possess anti inflammatory and antitumor properties (Shishodia et al., 2003). In spite of having such a broad range of therapeutic and antioxidant property, the major drawback associated with the use of curcumin is its low systemic bioavailability upon administration. Poor absorption from the intestine coupled with high degree of metabolism in the liver hinders the development of curcumin as a potent clinical agent (Yadav et al., 2012). Curcumin may inhibit chemotherapyinduced apoptosis in animal models of breast cancer via inhibition reactive oxygen species generation (Shishodia et al., 2003). Vitamin C, or ascorbic acid, has been a component of various dermatologic drugs and cosmetics for many years. It is known for its antioxidant properties and its applications in cancer therapy and inflammatory skin changes. (Albert SzentGyörgyi, 2010).a scorbate is a prooxidant anticancer therapy Through the production of $\mathrm{H}_{2} \mathrm{O}_{2}$, pharmacologic a scorbate can induce some cancer cell death in vitro and inhibit a number of types of tumor growth in animal models. Cetrimonium bromide (CTAB) belongs to a group of quaternary ammonium compounds, which also includes benzethonium chloride and dequalinium chloride, both of which have demonstrated anticancer properties in vitro and in vivo by targeting tumor mitochondria (Yip et al., 2006). Quaternary ammonium derivatives have also been reported to enhance antitumor activity when compared with their parent compounds (Giraud et al., 2002), suggesting that molecules may be highly effective anticancer agents. This study was aimed to study the potential therapeutic effect of Novel Nanocomoposites (Basic curcumin NP + Zinc Oxide NP) modified with vitamin $\mathrm{C}$ and $\mathrm{Cu}-\mathrm{CTAB}$ on tumor-induced in Female Mice.

\section{Material and Methods}

\subsection{Chemicals:}

Basic nanocurcumin and $\mathrm{ZnO}$ nanocomposit, surfactant (CTAB) purchased from Sigma-Aldrich (Sigma, USA) Company. Sodium Ascorbate purchased from El-Gomhoria Chemicals Company.

\subsection{Nanocompsite compound:}

(Basic nanocurcumin $3.75 \mathrm{gm}+\mathrm{ZnO}-$ nanocomposit $1.25 \mathrm{gm})$ modified with Vitamin C $1.0 \mathrm{gm}+$ Surfactant (CTAB) 0.1 gm)

\subsection{Preparations and Measurements of novel nanocomposite (Basic Curcumin \& Zinc Oxide)}

To prepare curcumin nanoparticles, $1 \mathrm{M}$ curcumin with low solubility in water was mixed with $4 \mathrm{M}$ sodium bicarbonate buffer, then grinded using mechanical ball mill (350 round/Sec) for $8 \mathrm{hrs}$. The colour of curcumin changed from yellow to red as a result of the curcumin sodium salt formation. Curcumin nanoparticles were then dispersed into $50 \mathrm{ml}$ of distilled water making aqueous solution, which was filled in a reactor that was immersed in a water bath adjusted at $11^{\circ} \mathrm{C}$. Afterwards, this reactor was placed in an ultrasound apparatus (VCX-750 commercial sonicator) and sonication was applied in continuous 
mode at 100 Watt in a glass reaction vessel with thin and indented bottom for uniform and more efficient energy transmission.

Zinc Oxide nps Modified with Basic Nanocurcumin Preparations: Modified ZnOnps was achieved by soaking ZnOnps for $24 \mathrm{~h}$ in basic nano-curcumin $0.05 \mathrm{~g}$ in $50 \mathrm{ml}$ distilled water and stirred overnight to allow complete complexation. The resulting solids were dried in an evacuated desicator to give Zinc oxide nps modified with basic nano-curcumin.

The novel formula drug was ball milled for 8 hours in the nanoscale to the corresponding nano drug as nano (Basic curcumin, Zinc Oxide) and we got TEM (Transmission electron microscobe . From the TEM studies represents TEM image of the novel nano composide (Basic curcumin, Zinc oxide) ranging from 6.87-12.7 $\mathrm{nm}$ in diameter and has spherical shape. Ultra sonication for nanocomposide drug by dissolving it in saline at concentrations of $5 \mathrm{~g} / \mathrm{L}$. Putting vitamin $\mathrm{C}$ and $\mathrm{Cu}-\mathrm{CTAB}$ with Nanocompsit.

\subsection{In vitro study (Cytotoxic assay):}

The antitumor effect and inhibitory concentration 50 (IC50) of this novel nanocompsite will be investigate against MPC-7 (breast carcinoma cell line).

\subsection{In vivo study:}

Acute Toxicity Study (Determination of LD50) for Nanocomposite according to (Finney, 1964)

\subsection{Animals:}

A total number of 80 Australian females albino mice of 12-14 weeks old age and weighting 25-30 gm were used in the experimental investigation of these study. Mice were obtained from the Research Institutes of Ophthalmology, Giza, Egypt. Animals were housed in separate metal cages, fresh and clean drinking water was supplied ad-libtium through specific nipple. Mice were kept at a constant environmental and nutritional condition throughout the period of the experiment.

\subsection{Tumor induction:}

The experimental induction of tumor in female mice was carried out at the National Cancer Institute Egypt. Every $1 \mathrm{ml}$ of Ehrlich ascites adenocarcinoma was diluted with $4 \mathrm{ml}$ of normal saline. Each mice was injected subcutaneously $(\mathrm{S} / \mathrm{C})$ in the medial aspect of the right thigh with $0.2 \mathrm{ml}$ of Ehrlich ascites adenocarcinoma $\left(2.5 \times 10^{6}\right.$ tumor cells with single cell suspension) (Zeinab, 2009). The tumor developed and become palpable in all injected animals at 5-7 days post tumor inoculation

\subsection{Experimental design:}

Mice were randomly divide into Four groups each one comprises of 20 mice kept in separate metal cages: Group 1: (NTBM) Normal mice act as (Normal control). Group 2: (TBM) Tumor bearing control group. Group 3: Mice treated with nanocompsite at dose of $(1.850 \mathrm{~g} / \mathrm{kg}$ b.wt/day) 6 weaks orally. Group 4: Tumor bearing mice treated with nanocompsite at dose of $(1.850 \mathrm{~g} / \mathrm{kg}$ b.wt/day) 6 weaks orally.

\subsection{Sampling:}

Liver tissues sample were collected in the morning after over night fasting from all mice by decapitation every $2,4,6$ weeks from the onset of treatment, then obtained in dry and clean plates then kept in a deep freeze at $-20^{\circ} \mathrm{C}$ until used for subsequent molecular analysis.

\subsection{Molecular analysis:}

\subsubsection{Total RNA isolation and quantitative real time PCR analysis for apoptotic markers:}

Total RNA was extracted by RNeasy mini Kit (Qiagen, Valencia, CA, USA) according to the manufacturer's instructions. Concentration of the extracted RNA was determined using Nanodrop 8000 spectrophotometer (Thermo- Scientific, Wilmington, DE), and the integrity of RNA was visualized on a $1 \%$ agarose gel using a gel documentation system (Universal Hood II, BioRad, Hercules, CA). The first strand 
of cDNA was synthesized from $1 \mu \mathrm{g}$ of total RNA by reverse transcriptase using $\mathrm{M}$ MLV (Promega, Madison, WI) and oligo (dT) primers (Promega) according to the manufacturer's protocol. Quantitative realtime PCR was performed by QuantiTect SYBR Green PCR kit (Qiagen) using an ABI PRISM 7900HT Sequence Detection System (Applied Biosystems, Foster City, CA). Two microliters of template cDNA was added to the final volume of $20 \mu \mathrm{L}$ of reaction mixture. Real-time PCR cycle parameters included 10 minutes at $95^{\circ} \mathrm{c}$ followed by 40 cycles involving denaturation at $95^{\circ} \mathrm{c}$ for 15 seconds, annealing at $60^{\circ} \mathrm{c}$ for 20 seconds, and elongation at $72^{\circ} \mathrm{c}$ for 20 seconds. The specific sets of primer for p53 and $\beta$-actin used in this study are given in our previous publication. 15 Expressions of selected genes were normalized to the $\beta$-actin gene, which was used as an internal housekeeping control. All the real-time PCR experiments were performed in triplicate, and data were expressed as the mean of at least three independent experiments.

\subsubsection{Apoptotic DNA ladder assay}

Apoptotic DNA ladder assay was performed in liver cells exposed to 15 $\mu \mathrm{g} / \mathrm{mL} \mathrm{ZnO}$ NPs for 24 hours. At the end of exposure, DNA was extracted using an apoptotic DNA Ladder Kit (Roche, Indianapolis, IN, Cat No. 11835246001). The extracted DNA was then evaluated on a $1 \%$ agarose gel using ethidium bromide. DNA fragmentation pattern was documented by a gel documentation system.

\subsubsection{Estimation of protein}

The total protein content was measured by the Bradford method (Bradford, 1976) using Bradford reagent (Sigma-Aldrich) and bovine serum albumin as the standard.

\subsection{Statistical analysis}

Statistical significance was determined by one-way analysis of variance followed by Dunnett's multiple comparison test. Significance was ascribed at $\mathrm{P}<0.05$. All analyses were conducted using the Prism software package (GraphPad Software, Version 5.0, GraphPad Software Inc., San Diego, CA).

\section{RESULTS}

Figure (1): Formaldehyde agarose gel electrophoresis analysis of total RNA in hepatic tissues of NTBM (1), TBM (2), treated NTBM (3) and treated TBM (4) liver. The integrity of total RNA samples assessed using agarose gel electrophoresis) of hepatic tissues that obtained from experimental mice showed different band thickness figure (1). The figure shows clear 18s and 28 s bands.
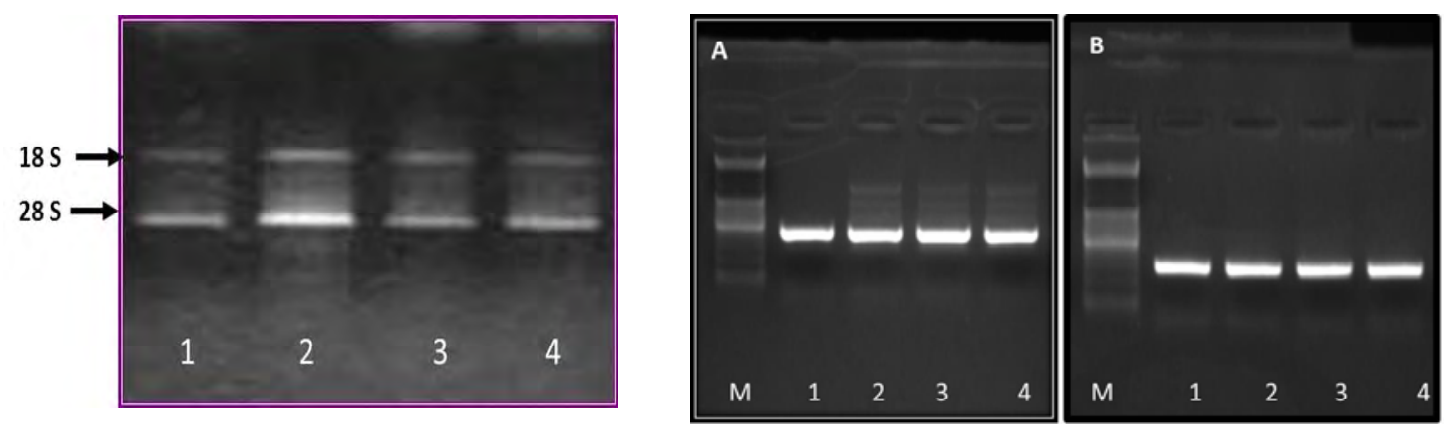
Figure (2): The Relative P53 Change \% of P53 amplicon from NTBM (1), TBM (2), treated NTBM (3) and treated TBM (4) liver.

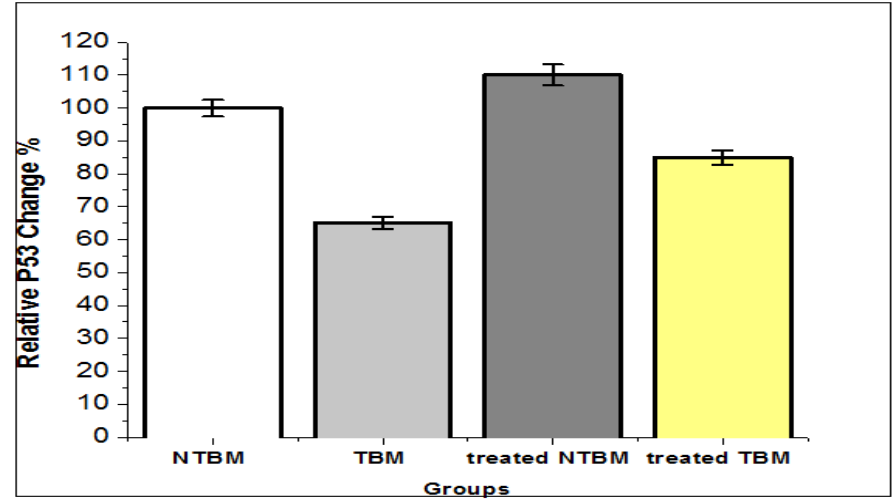

Figure (3): Representative gel image shows DNA fragmentation which was examined by the DNA laddering assay in hepatic tissues of NTBM (1), TBM (2), treated NTBM (3) and treated TBM (4) mice.

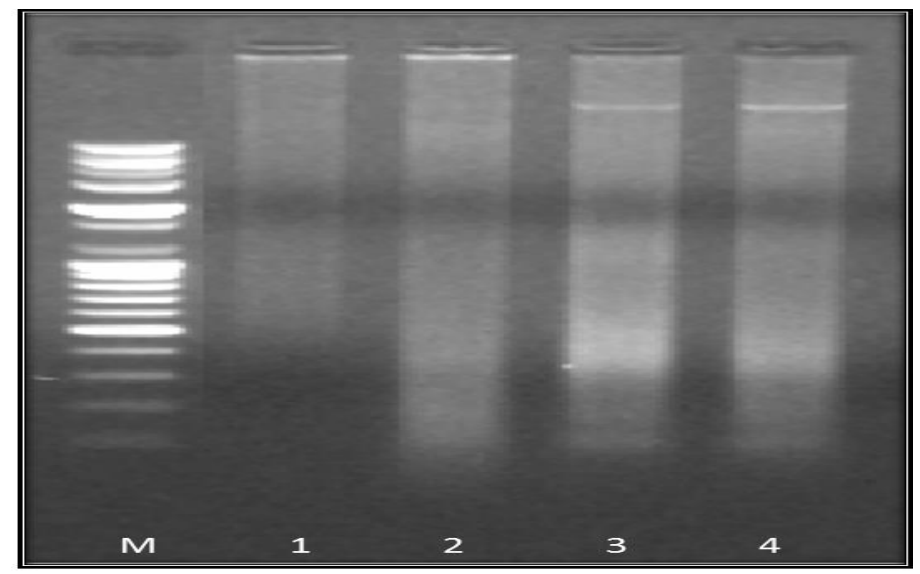

Figure (4): Normalized DNA Fragmentation Percentages to the Negative control.

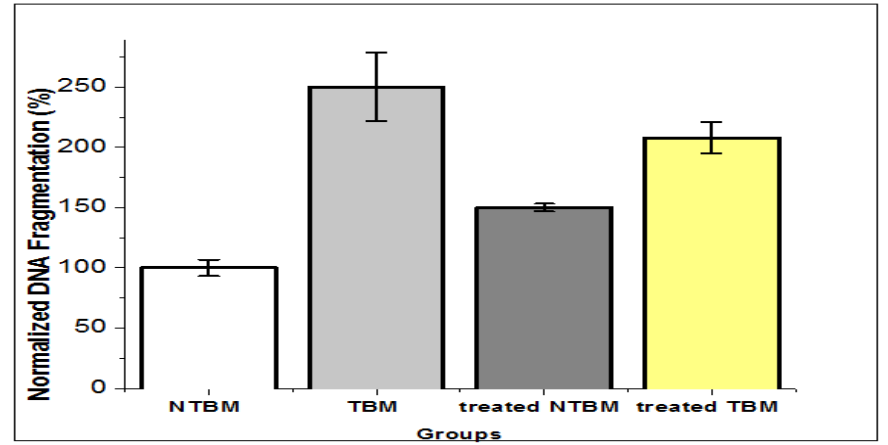


Figure (5): SDS-PAGE of proteins from NTBM (1), TBM (2), treated NTBM (3) and treated TBM (4) liver.

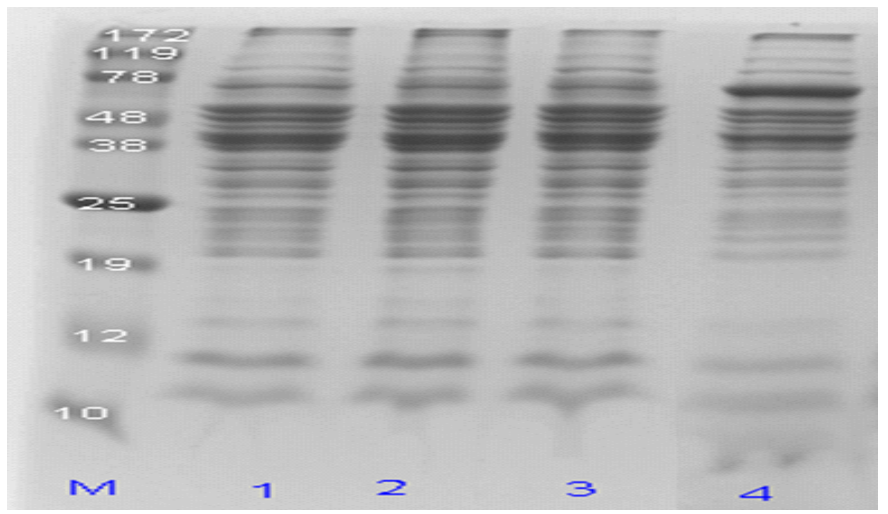

\section{DISCUSSION}

Our results in figures $(1 \& 2 \& 3 \& 4 \& 5 \&$ 6) showed Reverse transcriptase PCR results shown that $P 53$ mRNA expression level were decreased into $65 \pm 1.8$ in TBM and $85 \pm 2.2$ treated TBM when compared to controls $(100 \pm 2.5$ in NTBM and $110 \pm 3.2$ in treated NTBM) mice groups, a highly significant different between the TBM groups and the NTBM groups. Moreover, DNA fragmentation results shown that DNA damage level were decreased into $100 \pm 6.8$ in NTBM and $150 \pm 4.6$ treated NTBM when compared to TBM $(250 \pm 28.5)$ and treated $\operatorname{TBM}(208 \pm 12.9)$ in mice groups, a highly significant different between the TBM groups and the NTBM groups. On the other hand, the hepatic protein profiling results shown that indicate a highly significant different between the TBM groups and the NTBM groups in the high and low molecular weight proteins. This presented data confirmed by (George et al., 2009) who reported that, the toxicity of $\mathrm{ZnO}$ NPs has been ascribed to the release of $\mathrm{Zn}^{2+}$ ions. However, studies have also shown that the toxicity of ZnO NPs is due to their particulate nature, which may give rise to reactive oxygen species (ROS) (Moos et al., 2010). ROS generation is linked to DNA damage and cellular apoptosis (Cadet et al., 2010) and is also known to activate the mitogen activated protein kinase (MAPK) pathways and P53 which are important mediators of signal transduction and play a key role in regulating many cellular processes(Navarro et al., 2006). The NPs can lead to spontaneous ROS generation at their surface owing to their chemical and surface characteristics. They can also lead to the generation of free radicals after their interaction with cellular components, e.g., mitochondrial damage. Another way by which ROS is generated is through the activation of NADPH-oxidase enzyme, which is responsible for $\mathrm{O}_{2}^{-}$production in the membrane of phagocytic cells. In case of $\mathrm{ZnO} \mathrm{NPs}$, the generation of ROS has been attributed to their semiconductor and nano level characteristic, which leads to ROS generation even in the absence of light. The quality of $\mathrm{ZnO}$ nanocrystal decreases with size and results in increased interstitial zinc ions and oxygen vacancies (Sharma et al., 2009). These crystal defects can lead to a large number of electron-hole pairs, which can migrate to the nanoparticle surface and contribute to the ROS generation. The electrons and holes can react with the oxygen and hydroxyl ions, respectively, present in the aqueous environment of $\mathrm{ZnO}$ NPs. This produces highly reactive free radicals including the superoxide anion radical (from electrons) and the hydroxyl radical (from holes) (Rasmussen et al., 2010). When in contact with the cellular environment, these radicals can oxidize and reduce macromolecules 
(DNA, lipids, proteins) resulting in significant oxidative damage to cell. Some NPs owing to their small size are capable of reaching the nucleus and interact with DNA and they may also exhibit an indirect effect on DNA through their ability to generate ROS (Shukla et al., 2010). This DNA damage may either lead to carcinogenesis or cell death, thus disrupting normal cell functions. (Sharma et al., 2009) revealed the DNA damaging potential of these NPs in somatic cells (skin cells, lymphocytes) and germ cells . As ROS are known to react with DNA molecule causing damage to both purine and pyrimidine bases as well as the DNA backbone (Martinez et al., 2003). Apoptosis helps to establish a natural balance between cell death and cell renewal in mature animals by destroying excess, damaged, orility abnormal cells. The balance between survival and apoptosis, however,often tips toward the former in cancer cells. The major mechanism by which curcumin induces cytotoxicity in tumor cells is induction of apoptosis.Curcumin decreases the expression of antiapoptotic members of the Bcl-2 family and elevates the expression of p53, Bax, and procaspases-3, -8, and -9 . Several NF-kB-regulated genes, including Bcl-2, Bcl-XL, cIAP, survivin, TRAF1, and TRAF2, have been reported to function primarily by blocking the apoptosis pathway. (Aggarwal, 2004). In a study on melanoma cells, curcumin induced apoptosis independent of the level of p53 expression. It induced apoptosis in four cell lines with wild-type and four cell lines with mutant p53 without inducing additional expression of p53(Bush et al., 2001); in human breast cancer cells, however, curcumin induced apoptosis through p53dependent Bax induction.( Choudhuri et al., 2005). Curcumin also suppressed the growth of several T-cell leukemia cell lines in a dose-dependent manner.Curcumin was found to be highly cytotoxic toward several malignant colon cancer cell lines. Curcumin activates GADD153, which in turn acts as an activator of apoptosis (Scott and Loo,
2004) in human hepatoma G2 cell line, the cytotoxic action of curcumin is mainly through inducing DNA damage of both the nuclear and the mitochondrial genome. Curcumin induced p53-mediated apoptotic death in a dose- and time-dependent fashion in basal cell carcinoma lines (Jee et al., 1985). CTAB belongs to a group of quaternary ammonium compounds, which also includes benzethonium chloride and dequalinium chloride, both of which have demonstrated anti-cancer properties in vitro and in vivo by targeting tumor mitochondria (Yip et al., 2006). Quaternary ammonium derivatives have also been reported to show enhanced anti-tumor activity compared to their parent compounds (Giraud et al., 2002), suggesting that molecules possessing quaternary ammonium moieties may be highly effective anti-cancer agents. $\mathrm{CTAB}$ is a quaternary ammonium compound, belonging to a group of small molecules, known as delocalized lipophilic cations (DLCs). Due to their lipophilic nature and delocalized positive charge, DLCs can penetrate the hydrophobic barriers of plasma and mitochondrial membranes, and accumulate in the mitochondria in response to the negative transmembrane potential, resulting in mitochondriotoxicity (Kroemer, 2006). Once CTAB is concentrated into the tumor mitochondria, the $\mathrm{H}^{+}$-gradient across the inner mitochondrial membrane may begin to dissipate, with the consequent decline sensed by the mitochondrial permeability transition pore (PTP) (Green and Kroemer, 2004). Opening of the PTP causes mitochondrial outer membrane permeabilization (MOMP), a pivotal event in the intrinsic apoptotic pathway, leading to the disruption of essential mitochondrial functions, along with release of apoptogenic factors, such as cytochrome c (Kundu and Thompson, 2005). Increased cytosolic $\mathrm{Ca}^{2+}$ levels were also detected in cells with depolarized mitochondria, which may be associated with endoplasmic reticulum $\mathrm{Ca}^{2+}$ release during ER-stress induced apoptosis. Increased cytosolic $\mathrm{Ca}^{2+}$ can trigger 
mitochondrial $\mathrm{Ca}^{2+}$ overload, resulting subsequent MOMP and cytochrome c release, thereby activating the caspase cascade (Xu et al., 2005). The activation of initiator caspases-2 and -8 and p53 which was observed to a lesser extent in CTABtreated HNC cells, is also involved in the ER-stress response (Momoi, 2004). Collectively, this suggests that activation of both ER- and mitochondria-mediated apoptotic pathways is responsible for CTAB-induced cytotoxicity. Fantin and Leder, (2006) have demonstrated that CTAB compromises mitochondrial bioenergetic regulation via inhibition of ATP synthase, which consists of the membrane-embedded $\quad \mathrm{F} 0 \quad(\mathrm{H}+-$ translocation) and peripheral catalytic F1 (ATP synthesis/hydrolysis) subcomplexes (Capaldi and Aggeler, 2002). The ATPase couples the electrochemical $\mathrm{H}+$-gradient to ATP synthesis/hydrolysis and is responsible for maintaining the $\mathrm{M}$ in response to changes in the proton motive force (Suzuki et al., 2003). Thus, mitochondrial repolarization via ATP hydrolysis may occur to counteract the CTAB-induced depolarization in cancer cells. The desirable anti-cancer activity of CTAB suggests that analogues based on structural modification may result in more efficacious lead compounds. As such, commercially available derivatives were exploited to examine the structure-function relationship of CTAB. The structure indicate that the combination of both the positively charged quaternary nitrogen and non-polar hydrophobic alkyl chain are indispensable for its cytotoxic effect. This inhibitory action also appeared to be highly dependent on the length of the alkyl chain, as analogues with shorter tails exhibited reduced cytotoxicity. Additional testing of cetrimonium analogues with longer alkyl chains may provide useful starting points for further lead optimization. Taken together, (Yip et al., 2006) suggest that the positively charged polar head of CTAB provides the basis for its anti-cancer specificity, while the non-polar hydrophobic tail may aid in its insertion into the plasma membrane. The lipophilic nature, delocalized positive charge, and structural similarity to sphingosine, a primary component of sphingolipids, may allow CTAB to readily penetrate the hydrophobic barriers of the lipid bilayer and accumulate within the tumor cell. Although vitamin $\mathrm{C}$ is a well-known anti-oxidant as well as an essential nutrient, there are numerous reports regarding its tumoricidal effects. It induces apoptosis via the disruption of mitochondrial membrane potential and the suppression of the translocation of transferring receptor from cytosol to membrane (Kang et al., 2005). In addition, vitamin $\mathrm{C}$ suppresses the proliferation of cancer cells through the growth arrest at G1 stage that is closely related with the modulation of the activity of p53-p21Waf1/Cip1 and CDK2 (Kim et al., 2008). The productions of factors that are involved in the metastasis are also down-regulated by vitamin $\mathrm{C}$ treatment (Kim et al., 2011). In cancer therapy, vitamin $\mathrm{C}$ has a great potential on the reduction of the side effects of chemotherapeutic drugs as well as the increasing of therapeutic efficacy. It has been reported that vitamin $\mathrm{C}$ prevents proliferation and metastasis of cancer cells (Kim et al., 2008). Moreover, it could induce apoptosis in cancer cells via the disruption of mitochondrial membrane potential (Kang et al., 2003). It is wellknown mitochondria and ER are important intracellular organelles during the TNFreceptor independent apoptosis pathway, but the specific action mechanisms of vitamin $\mathrm{C}$ on the induction of apoptosis via the modulation of ER function by an alteration of calcium concentration or redox state induces apoptosis (Li et al., 2006). Cisplatin plus vitamin $\mathrm{C}$ treatment resulted in significantly increased apoptosis along with upregulation of p53 compared to untreated cells and/or Cisplatin -treated cells. These results suggest that vitamin C enhanced sensitivity and apoptosis via upregulation of p53. (An et al., 2011) 


\section{Conclusion \& Recommendation}

The marked difference in cytotoxicity between cancer cells and normal cells suggests an exciting potential for (Basic nanocurcumin $+\mathrm{ZnO} \mathrm{NP}+$ Vitamin $\mathrm{C}+$ $\mathrm{Cu}-\mathrm{CTAB}$ ) as novel alternatives to cancer therapy. Our molecular data showed that both mRNA and protein levels of tumor suppressor gene p53 were upregulated in nanocompsite treated human liver cancer cell. Moreover, a novel nanocompsit also found to induce activity of DNA fragmentation liver cells. This study suggests that (Basic nanocurcumin $+\mathrm{ZnO}$ $\mathrm{NP}+$ Vitamin $\mathrm{C}+\mathrm{Cu}-\mathrm{CTAB})$ induce apoptosis in cancer cells, which is mediated by ROS via p53 pathways through which most of the anticancer drugs trigger apoptosis.

\section{REFERENCE}

Aggarwal, B.B., Indra, D., Bhatt, H.I., Kwang, S.A., Gautam, S., Santosh, K. S., Chitra, N., Navindra, S., Shishir, S. 2006. Turmeric: The Genus Curcuma. 7034. book fm Page 297 Monday, July 24.

Albert Szent-Györgyi. Philadelphia. 2010. Chemical Heritage Foundation. p. 1-3. Available at: http://www. chemheritage.org/.

An, S.H., Kang, J.H., Kim, D.H., Lee, M.S. 2011. Vitamin $C$ increases the apoptosis via up-regulation p53 during cisplatin treatment in human colon cancer cells. J. Biol. Chem. 281: 72607270

Bradford, M.M. 1976. A rapid and sensitive method for the quantitation of microgram quantities of protein utilizing the principle of protein-dye binding. Anal Biochem. 72: 248-254.

Bush, J.A., Cheung, K.J, Jr, Li, G. 2001. Curcumin induces apoptosis in human melanoma cells through a Fas receptor/caspase-8 pathway independent of p53. Exp Cell Res 271(2) : 305-14.
Cadet, J., Douki, T., Ravanat, J.L. 2010. Oxidatively generated base damage to cellular DNA. Free Radic Biol Med 49(1): 9-21.

Capaldi, R.A., Aggeler, R. 2002. Mechanism of the F (1)F(0)-type ATP synthase, a biological rotary motor. Trends Biochem Sci; 27: 154-160.

Choudhuri, T., Pal, S., Das, T., Sa, G. 2005. Curcumin selectively induces apoptosis in deregulated cyclin D1expressed cells at G2 phase of cell cycle in a p53-dependent manner. $\mathrm{J}$ Biol Chem 280(20): 20059-68

Fantin, V.R., Leder P. 2006. Mitochondriotoxic compounds for cancer therapy. Oncogene 25: 47874797.

Farnebo, M., Bykov, V.N., Wiman, K.G. 2010. The p53 tumor suppressor: a master regulator of diverse cellular processes and therapeutic target in cancer. Biochem Biophys Res Commun 396: 85-89.

Finney, D. J. 1964. Stastical method in biological assay. $2^{\text {nd }}$ Edition, Charless Griffin and Co., LTd., London, England.

George, S., Pokhrel, S., Xia, T., Gilbert, B., Ji, Z., Schowalter, M. 2009. Use of a rapid cytotoxicity screening approach to engineer a safer zinc oxide nanoparticle through iron doping. ACS Nano 4(1):15-29.

Giraud, I., Rapp, M., Maurizis, J.C., Madelmont, J.C. 2002. Synthesis and in vitro evaluation of quaternary ammonium derivatives of chlorambucil and melphalan, anticancer drugs designed for the chemotherapy of chondrosarcoma. J Med Chem 45: 2116-2119.

Green, D.R., Kroemer, G. 2004. The pathophysiology of mitochondrial cell death. Science 305: 626-629.

Jee, SH., Shen, S.C., Tseng, C.R., Chiu, H.C., Kuo, M.L. 1998. Curcumin induces a p53-dependent apoptosis in human basal cell carcinoma cells. J Investig Dermatol 111: 656-661. 
Kang, J. S., Cho, D., Kim, Y.I., Hahm, E., Kim, Y.S., Jin, S.N., Kim, H.N., Kim, D., Hur, D., Park, H., Hwang, Y.I., Lee, W.J. 2005. Sodium ascorbate (vitamin C) induces apoptosis in melanoma cells via the down-regulation of transferrin receptor dependent iron uptake. J. Cell. Physiol. 204:192-197.

Kang, J. S., Cho, D., Kim, Y.I., Hahm, E., Kim, Y.S., Jin, S.N., Kim, H.N.,Kim, D., Hur, D., Park, H., Hwang, Y.I., Lee, W.J. 2003. L-ascorbic acid (vitamin C) induces the apoptosis of B16 murine melanoma cells via a caspase-8independent pathway. Cancer Immunol. Immunother. 52: 693-698.

Kim, H. N., Kim, H., Kong, J.M., Bae, S., Kim, Y.S., Lee, N., Cho, B.J., Lee, S.K., Kim, H.R., Hwang, Y.I., Kang, J.S., Lee, W.J. 2011. Vitamin C downregulates VEGF production in $\mathrm{B} 16 \mathrm{~F} 10$ murine melanoma cells via the suppression of $\mathrm{p} 42 / 44$ MAPK activation. J. Cell. Biochem. 112: 894901.

Kim, J. E., Jin, D.H., Lee, S.D., Hong, S.W., Shin, J.S., Lee, S.K., Jung, D.J., Kang, J.S., Lee, W.J. 2008. Vitamin C inhibits p53-induced replicative senescence through suppression of ROS production and p38 MAPK activity. Int. J. Mol. Med. 22: 651-655.

Kroemer, G. 2006. Mitochondria in cancer. Oncogene 25: 4630-4632.

Kundu, M., Thompson, C.B. 2005. Macroautophagy versus mitochondrial autophagy: a question of fate? Cell Death Differ; 12 (2): 1484-1489.

Lee, J.H., Huh, Y.M., Jun, Y.W., Seo, J.W., Jang, J.T, Song, H.T. 2007. Artificially engineered magnetic nanoparticles for ultra-sensitive molecular imaging. Nat Med. 13: 95-99.

Li, J., Lee, B., Lee, A.S. 2006. Endoplasmic reticulum stress-induced apoptosis: multiple pathways and activation of p53-up-regulated modulator of apoptosis (PUMA) and NOXA p 53.

Martinez, G.R., Loureiro, A.P, Marques, S.A., Miyamoto, S., Yamaguchi, L.F.,
Onuki, J. 2003. Oxidative and alkylating damage in DNA. Mutat Res 544(2-3): 115-127.

Momoi, T. 2004. Caspases involved in ER stress-mediated cell death. J Chem Neuroanat 28: 101-105.

Moos, P.J, Chung, K., Woessner, D., Honeggar, M., Cutler, N.S., Veranth, J.M. 2010: $\mathrm{ZnO}$ particulate matter requires cell contact for toxicity in human colon cancer cells. Chem Res Toxicol 23(4): 733-739.

Navarro, R., Busnadiego, I., Ruiz-Larrea, M.B., Ruiz-Sanz, J.I. 2006. Superoxide anions are involved in doxorubicininduced ERK activation in hepatocyte cultures. Ann N Y Acad Sci 1090: 419428.

Premanathan, M., Karthikeyan, K., Jeyasubramanian, K., Manivannan, G. 2011. Selective toxicity of $\mathrm{ZnO}$ nanoparticles toward Gram positive bacteria and cancer cells by apoptosis through lipid peroxidation. Nanomedicine: NBM. 7: 184-192.

Rasmussen, J.W., Martinez, E., Louka P, Wingett DG 2010. Zinc oxide nanoparticles for selective destruction of tumor cells and potential for drug delivery applications. Expert Opin Drug Deliv 7(9): 1063-1077.

Scott, D.W., Loo, G. 2004. Curcumininduced GADD153 gene up-regulation in human colon cancer cells. Carcinogenesis. 25(11): 2155-64.

Sharma, V., Shukla, R.K., Saxena, N., Parmar, D., Das, M., Dhawan, A. 2009 - DNA damaging potential of zinc oxide nanoparticles in human epidermal cells. Toxicol Lett 185(3): 211-218.

Sherr, C.J. 2004. Principles of tumor suppression. Cell. 11: 235-246.

Shishodia, P., Potdar, C.G., Gairola, B.B., Aggarwal, B.B. 2003. Curcumin (diferuloylmethane) down-regulates cigarettesmoke-induced NF-kappaB activation through inhibition of IkappaBalpha kinase in human lung epithelial cells: correlation with 
suppression of COX-2, MMP-9 and cyclin D1, Carcinogenesis 24:12691279.

Shukla, R.K., Sharma, V., Pandey, A.K., Singh, S., Sultana, S., Dhawan, A. 2010. ROS-mediated genotoxicity induced by titaniumdioxide nanoparticles in human epidermal cells. Toxicol In Vitro 25:231-241

Suzuki, T., Murakami, T., Iino, R. 2003. F0F1-ATPase/synthase is geared to the synthesis mode by conformational rearrangement of epsilon subunit in response to proton motive force and ADP/ATP balance. J Biol Chem 278: 46840-46846.

Wu, Y.N., Chen, D.H., Shi, X.Y., Lian, C.C., Wang, T.Y., Yeh, C.S. 2011. Cancer-cell-specific cytotoxicity of non-oxidized iron elements in iron core-gold shell NPs. Nanomedicine: NBM.; 7: 420-427.

$\mathrm{Xu}$, C., Bailly, B., Reed, J.C. 2005. Endoplasmic reticulum stress: cell life and death decisions. J Clin Invest; 115: 2656-2664.

Yadav, A., Lomash, V., Samim, M., Flora, S.J. 2012. Curcumin encapsulated in chitosan nanoparticles: a novel strategy for the treatment of arsenic toxicity. Chem Biol Interact 199: 49-61

Yip, K.W., Mao, X., Au, P.Y. 2006. Benzethonium chloride: a novel anticancer agent identified by using a cell-based small-molecule screen. Clin Cancer Res 12: 5557-5569.

Zeinab, E.H. 2009. Ginger extract antimutagens as cancer chemopreventive agent against Ehrlich Ascites Carcinoma. Academic Journal of Cancer research 2(2): 61-67.

Zhang, H., Chen, B., Jiang, H., Wang, C., Wang, H., Wang, X. 2011. A strategy for $\mathrm{ZnO}$ nanorod mediated multi-mode cancer treatment. Biomaterials. 32: 1906-1914. 